\title{
Pressor sensitivity to tyramine in patients with headache: relationship to platelet monoamine oxidase and to dietary provocation
}

\author{
R PEATFIELD,${ }^{*} \ddagger$ JULIA T LITTLEWOOD,$\dagger$ VIVETTE GLOVER, $\dagger$ M SANDLE,$\dagger F$ \\ CLIFFORD ROSE*
}

\begin{abstract}
From the Department of Neurology, Charing Cross Hospital Medical School, ${ }^{*}$ and the Bernard Baron Memorial Research Laboratories and Institute of Obstetrics and Gynaecology, Queen Charlotte's Hospital, $\dagger$ London, $U K$
\end{abstract}

SUMMARY The pressor responses to oral and intravenous tyramine were not different from controls in migrainous patients with or without a history of attacks triggered by foods. However, patients who reported a dietary trigger were more likely to develop headache after tyramine administration than those without such a dietary history. Pressor responses to intravenous tyramine in patients with cluster headache were indistinguishable from controls. A group of five males with platelet monoamine oxidase activity one standard deviation or more below that of male controls required less intravenous tyramine to raise blood pressure by $30 \mathrm{~mm} \mathrm{Hg}$ than males with monoamine oxidase levels within one standard deviation of the controls. This finding suggests that platelet monoamine oxidase activity to some extent reflects that of total body monoamine oxidase A plus B.

Tyramine, which is present in many foodstuffs, may provoke a hypertensive response (the "cheese effect") in patients taking monoamine oxidaseinhibiting drugs. ${ }^{12} \mathrm{~A}$ superficial similarity between the list of foods contraindicated in this group and those believed by some migrainous patients to initiate their migraine attacks led Hanington ${ }^{3}$ to postulate that tyramine might similarly be a cause of dietary migraine. Hanington ${ }^{34}$ also suggested that a deficiency of monoamine oxidase might account for the susceptibility of some migraine patients to tyramine-containing foods. In man the only peripheral source of this enzyme readily available for clinical study is the platelet, which contains solely the B form. ${ }^{5}$ Sandler $e t$ al. ${ }^{6}$ first reported a transitory deficiency of monoamine oxidase B during a migraine attack, which received subsequent confirmation. ${ }^{78}$ In addition, lower values have been demonstrated in certain patients between attacks ${ }^{9-11}$ although careful analysis of a large series points to the phenomenon being limited to male patients. ${ }^{11}$

\footnotetext{
$\ddagger$ Present address and address for reprint requests: Department of Neurology, Leeds General Infirmary, Great George Street, Leeds 1

Received 15 December 1982 and in revised form 9 April 1983. Accepted 16 April 1983
}

The mean and range of platelet monoamine oxidase activity, however, in patients believing dietary factors to initiate their attacks are no different from values in those who do not. ${ }^{81011}$ Particularly low activity has been indentified in patients with cluster headache $^{911}$ who seldom ascribe their attacks to dietary factors other than alcoholic beverages.

Tyramine is an indirectly acting pressor agent ${ }^{12-14}$ and Ghose et al. ${ }^{15}$ have claimed that migrainous subjects are more sensitive to its intravenous administration than control subjects. Oral tyramine does not appear to have been studied in this context. If platelet monoamine oxidase reflects enzyme activity elsewhere in the body, measurements in this tissue might thus provide some index of ability to inactivate tyramine.

The studies reported here were designed to test the pressor response of affected subjects to oral and intravenous tyramine in relation both to platelet monoamine oxidase activity and to history of dietary provocation.

\section{Patients and methods}

We had previously measured platelet monoamine oxidase activity in 109 female and 47 male migraine subjects, and 
in 37 male subjects with cluster headache ${ }^{11}$ (Littlewood J, Glover V, Sandler M, Petty R, Peatfield R and Rose FC, in preparation). These patients were subdivided into those with and without a history of dietary provocation of their headache. From the migrainous group, some patients were selected with activity values at least one standard deviation (SD) below the normal mean for their sex. As platelet monoamine oxidase activity and dietary history were not significantly related, a $2 \times 2$ factorial design could be used. Intravenous tyramine tests were performed on 21 patients and oral studies on 14 of them; intravenous tests were also carried out on six controls drawn from departmental staff, five of whom also received oral tyramine. In addition, intravenous tests were performed in three patients with cluster headache in an active phase (without prior monoamine oxidase measurement) and in six with quiescent cluster headache, five of whom had low platelet activity. Written consent was obtained from all patients and the project was approved by the Charing Cross Hospital Ethical Committee. All subjects discontinued any prophylactic medication at least $24 \mathrm{~h}$ before the tests and fasted overnight before the oral tests. There were no significant ECG abnormalities in any of the patients. Platelets were prepared for monoamine oxidase assay" on the same day as the intravenous pressor test and the result expressed as number of standard deviations from the normal mean for the subject's sex. The patients were telephoned at home 24 to $48 \mathrm{~h}$ after each test and asked about any subsequent development of headache.

\section{Intravenous tests}

The protocol was based on that of Ghose et al. ${ }^{16}$ The patients rested recumbent and a blood sample was taken for platelet monoamine oxidase determination. The intravenous cannula was left in situ, and kept patent with $0.9 \%$ saline solution. Blood pressure was measured with a Bard medical automatic sphygomomanometer which provides a digital readout of pulse, and systolic and diastolic blood pressures. After initial stabilisation, a bolus injection of tyramine was given; readings were then made every 30 to $40 \mathrm{~s}$, continuing through the rise and fall until the pressure started to rise again, whereupon the next dose was given. Doses of $0 \cdot 5,1,2$ and 4 and sometimes $8 \mathrm{mg}$ were given at approximately 5 min intervals until the blood pressure rise exceeded $20 \mathrm{~mm} \mathrm{Hg}$. For analysis, the mean of the rise and subsequent fall after each dose was recorded. A best fit dose response curve was prepared from the pressor effects of 1,2 and 4 and, when available, $8 \mathrm{mg}$ of tyramine and the result expressed as dosage $(\mathrm{mg} / \mathrm{kg}$ body weight) needed to raise the systolic blood pressure by $30 \mathrm{~mm} \mathrm{Hg}$.

\section{Oral tyramine}

The experimental protocol was modified from that of Elsworth et al. ${ }^{17}$ Capsules containing $25 \mathrm{mg}$ and $200 \mathrm{mg}$ of tyramine were prepared, and fasting patients were given $100 \mathrm{mg}$ and $200 \mathrm{mg}$ in separate doses, 30 to $40 \mathrm{~min}$ apart. Pulse and blood pressure were recorded every $5 \mathrm{~min}$, the latter by manual external sphygmomanometry. Again the mean of the blood pressure rise and subsequent fall was recorded.

\section{Results}

\section{Intravenous tyramine}

Mean doses required to produce a $30 \mathrm{~mm} \mathrm{Hg}$ rise in blood pressure are shown in table 1 . In many cases, the pressor response to $0.5 \mathrm{mg}$ of tyramine was disproportionately greater than the responses to higher doses, but Wilcoxon tests on the actual blood pressure rise induced by 0.5 and $4 \mathrm{mg}$ of tyramine showed no significant differences between subject groups. Wilcoxon Rank Sum tests showed no significant differences between migrainous patients and controls, dietary and non-dietary migrainous patients, active and quiescent cluster headache patients, and all the cluster headache patients compared with control subjects. For the 21 migrainous patients, there was no correlation between tyramine dose necded and time since last headache $(r=0.12$, NS). There was no significant difference between all male and female subjects (Wilcoxon Rank Sum test). There was no significant correlation between monoamine oxidase activity and the dose of tyramine needed to produce a $30 \mathrm{~mm} \mathrm{Hg}$ rise, in any diagnostic category.

The only significant result was obtained when the small group of males with low monoamine oxidase activity (more than one SD below the mean for male controls) was compared with the 15 other males tested. The former needed significantly less intravenous tyramine $(\mathrm{p}<0.05$; two-tailed Student's $t$ test) to produce a $30 \mathrm{~mm} \mathrm{Hg}$ rise in blood pressure. When the two males with active cluster headache were excluded from the 15 , the difference between the two groups became even more significant $(p<0.02)$. The male with common migraine with the lowest monoamine oxidase activity $(2.2 \mathrm{nmoles}$ tyramine oxidized $/ 30 \mathrm{~min} / \mathrm{mg}$ protein compared with the mean for male controls of 16.6) needed $47.4 \mu \mathrm{g} / \mathrm{kg}$ of intravenous tyramine, compared with mean of $76.8 \mu \mathrm{g} / \mathrm{kg}$ required by the controls. There was only one female with activity less than one SD below that of female controls. Her platelet monoamine oxidase activity was 9 nmoles tyramine oxidized $/ 30 \mathrm{~min} / \mathrm{mg}$ protein and she needed $86 \mu \mathrm{g}$ of tyramine $/ \mathrm{kg}$ to raise blood pressure by $30 \mathrm{~mm} \mathrm{Hg}$.

The patients' subsequent headaches are tabulated in table 2. It will be seen that more of the dietary patients did develop headaches; the time of onset was highly variable, though the earlier headaches were significantly more severe $(p<0.01-$ Spearman Rank Correlation test). Two of the six control subjects developed trivial headaches but none of the cluster headache patients experienced any pain whatsoever. Intensity of subsequent headache in migrainous patients was not related to actual rise in 
Table 1 Pressor effects of intravenous tyramine

\begin{tabular}{|c|c|c|c|}
\hline & $n(F / M)$ & $\begin{array}{l}\text { Monoamine oxidase activity } \\
d^{*} \pm S E M\end{array}$ & $\begin{array}{l}\text { Tyramine dosage } \pm S E M \\
\text { ( } \mu \mathrm{g} / \mathrm{kg} \text { to raise blood } \\
\text { pressure by } 30 \mathrm{~mm} \mathrm{Hg})\end{array}$ \\
\hline $\begin{array}{l}\text { All migraine } \\
\text { All non-dietary } \\
\text { All dietary } \\
\text { All males with monoamine oxidase greater }\end{array}$ & $\begin{array}{l}21(14 / 7) \\
13(8 / 5) \\
8(6 / 2)\end{array}$ & $\begin{array}{l}-0.08 \pm 0.25 \\
-0.19 \pm 0.36 \\
+0.09 \pm 0.30\end{array}$ & $\begin{array}{l}81 \cdot 3 \pm 7 \cdot 2 \\
75 \cdot 2 \pm 5 \cdot 8 \\
91 \cdot 3 \pm 15 \cdot 8\end{array}$ \\
\hline $\begin{array}{l}\text { than one SD below controls } \\
\text { All other males } \\
\text { Quiescent cluster } \\
\text { Active cluster } \\
\text { All cluster } \\
\text { Control }\end{array}$ & $\begin{array}{l}5(0 / 5) \\
15(0 / 15) \\
6(0 / 6) \\
3(1 / 2) \\
9(1 / 8) \\
6(1 / 5)\end{array}$ & $\begin{array}{l}-1.9 \pm 0.35 \\
-0.52 \pm 0.11 \\
-1.24 \pm 0.28 \\
-0.28 \pm 0.16 \\
-0.92 \pm 0.25 \\
+0.37 \pm 0.28\end{array}$ & $\begin{array}{l}54 \cdot 3 \pm 6 \cdot 7 \dagger \\
84 \cdot 3 \pm 11 \cdot 5 \\
87 \cdot 2 \pm 26 \cdot 7 \\
59 \cdot 3 \pm 18 \cdot 4 \\
77 \cdot 9 \pm 18 \cdot 6 \\
76 \cdot 8 \pm 8 \cdot 6\end{array}$ \\
\hline
\end{tabular}

†Different from all other males $(p<0.05)$

$\mathrm{d}^{*}=$ mean of the number of standard deviations from the mean of the control activity for the same sex.

Table 2 Numbers of patients reporting headache in each subjective severity grade after oral or intravenous tyramine administration. The numbers of hours before the onset of each headache are shown in brackets. $p$ values comparing the proportion of dietary and non-dietary patients developing headache are shown below

\begin{tabular}{|c|c|c|c|c|c|c|}
\hline \multirow[t]{2}{*}{ Headache severity grade } & \multicolumn{3}{|c|}{ Intravenous tyramine } & \multicolumn{3}{|c|}{ Oral tyramine } \\
\hline & $\begin{array}{c}\text { Dietary } \\
\text { patients }\end{array}$ & $\begin{array}{l}\text { Non-dietary } \\
\text { patients }\end{array}$ & Controls & $\begin{array}{c}\text { Dietary } \\
\text { patients }\end{array}$ & $\begin{array}{l}\text { Non-dietary } \\
\text { patients }\end{array}$ & Controls \\
\hline $\begin{array}{l}\text { Worse than usual } \\
\text { As bad as usual } \\
\text { Definite headache } \\
\text { Trivial headache } \\
\text { Nil } \\
\end{array}$ & $\begin{array}{l}1(0 \cdot 5) \\
1(1) \\
3(3,4,14) \\
1(13) \\
2 \\
8\end{array}$ & $\begin{array}{l}0 \\
1(22) \\
1(4) \\
2(2,2) \\
9 \\
13\end{array}$ & $\begin{array}{l}0 \\
0 \\
0 \\
2(0 \cdot 5,2) \\
4 \\
6\end{array}$ & $\begin{array}{l}0 \\
3 \\
3 \\
0 \\
1 \\
7\end{array}$ & $\begin{array}{l}0 \\
0 \\
0 \\
2 \\
5 \\
7\end{array}$ & $\begin{array}{l}0 \\
0 \\
2(0 \cdot 5,1 \cdot 5) \\
1(3) \\
2 \\
5\end{array}$ \\
\hline $\begin{array}{l}\text { All headache } v s \text { no headache } \\
\text { Definite or worse headache } \\
v s \text { no or trivial headache }\end{array}$ & \multicolumn{3}{|c|}{$p=0.13\left(\chi^{2}\right)$} & \multicolumn{3}{|c|}{$p=0 \cdot 103$ (Fisher's) } \\
\hline
\end{tabular}

Table 3 Pressor effects of oral tyramine

\begin{tabular}{|c|c|c|c|}
\hline & $n(F / M)$ & $\begin{array}{l}\text { Monoamine oxidase activity } \\
d^{*} \pm S E M\end{array}$ & $\begin{array}{l}\text { Tyramine dosage } \pm S E M \\
\text { ( } \mu \mathrm{g} / \mathrm{kg} \text { to raise blood } \\
\text { pressure by } 30 \mathrm{~mm} \mathrm{Hg} \text { ) }\end{array}$ \\
\hline $\begin{array}{l}\text { All migraine } \\
\text { All non-dietary } \\
\text { All dietary } \\
\text { Control }\end{array}$ & $\begin{array}{r}14(8 / 6) \\
7(3 / 4) \\
7(5 / 2) \\
5(1 / 4)\end{array}$ & $\begin{array}{l}-0.21 \pm 0.31 \\
-0.58 \pm 0.48 \\
+0.17 \pm 0.33 \\
-0.26 \pm 0.32\end{array}$ & $\begin{array}{l}6 \cdot 5 \pm 1.4 \\
8 \cdot 4 \pm 2 \cdot 5 \\
4 \cdot 6 \pm 0.7 \\
7 \cdot 1 \pm 1.4\end{array}$ \\
\hline
\end{tabular}

$\mathrm{d}^{*}$ defined as in Table 1.

the blood pressure (Wilcoxon Rank Sum test NS).

\section{Oral tyramine}

The mean doses $(\mathrm{mg} / \mathrm{kg})$ required to raise the blood pressure by $30 \mathrm{~mm} \mathrm{Hg}$ for the various sub-groups of migrainous patients are shown in table 3 . Responses to the $100 \mathrm{mg}$ dose did not differ significantly between the subject groups (Wilcoxon Rank Sum tests): Wilcoxon tests on the actual pressor response to $200 \mathrm{mg}$ revealed no significant differences between migrainous patients and controls, nor between dietary and non-dietary patients. Again, there was no significant difference between male and female subjects (Wilcoxon Rank Sum test). Only two males with platelet monoamine oxidase activity confirmed to be more than one SD below the mean for male controls, could be included in this study. One of these with platelet monoamine oxidase activity of 2.2 nmoles tyramine oxidised $/ 30 \mathrm{~min} / \mathrm{mg}$ protein needed $5.2 \mathrm{mg}$ oral tyramine, the other with a platelet monoamine oxidase activity of 10.9 needed $15.4 \mathrm{mg}$ of tyramine. Nevertheless, there was no significant correlation between monoamine oxidase 
activity and the tyramine dose needed, either in all the patients together or in each individual diagnostic category.

As with the intravenous tyramine studies, more of the dietary migraine patients developed headaches (table 2) but again there was wide variation in time of onset (the earlier the more severe: $p<0.01-$ Spearman Rank Correlation test). On this occasion, the difference between the dietary and non-dietary migrainous patients was significant $(p=0.005$, Fisher's exact test, two-tailed). Two of the five control subjects, however, developed definite headache and one a trivial one. The intensity of subsequent headache in migrainous patients was again not related to the actual rise in blood pressure (Wilcoxon Rank Sum test - NS).

\section{Discussion}

We have found no significant difference in pressor response to oral or intravenous tyramine in migrainous patients as a whole nor in those with and without a dietary history. We did, however, find that males with low platelet monoamine oxidase activity were significantly more sensitive to intravenous tyramine than other males. Unfortunately it was not possible to test the same groups with oral tyramine. However, the individual with the lowest platelet monoamine oxidase activity did not appear to be excessively sensitive to oral tyramine although the dose of intravenous tyramine he required was about half that of controls. One might expect a decrease of platelet monoamine oxidase activity of this order (2.9 SD below control) brought about by the administration of an monoamine oxidase inhibitor to be associated with substantially greater sensitivity to both oral and intravenous tyramine. It is unlikely that low whole body levels of monoamine oxidase B alone would affect the tyramine pressor response to any considerable extent. (-)-Deprenyl which, in suitable doses, totally inhibits monoamine oxidase $\mathrm{B}$, does not augment the tyramine pressor response, and may indeed have some independent protective action. In the pig, at least, the response to intravenous tyramine is not related to inhibition of tyramine oxidation. ${ }^{18}$ It seems possible that inhibition of the oxidation of released noradrenaline by monoamine oxidase A plays an important part in the development of the tyramine pressor response. The results obtained here thus suggest that platelet monoamine oxidase activity might provide some index, albeit a crude one, of the totality of monoamine oxidase A plus $B$ in the whole body.

We have been unable to confirm the finding of Ghose et al. ${ }^{16}$ that migrainous patients as a whole have a greater pressor response to intravenous tyramine than control subjects. Although $46 \%$ of their patients developed headache after intravenous tyramine pressor tests, they did not find a correlation between this phenomenon and any prior history of dietary sensitivity.

Unlike migraine proper, cluster headache is not associated with dietary provocation, with the exception of alcohol beverages. Our intravenous studies in cluster headache patients have shown them to be no more sensitive to tyramine than control subjects, and there was no convincing difference between those in active and quiescent phase of the illness. One of the "active" patients, however, did appear to be excessively sensitive to small doses of tyramine. Even so, this amine was quite unable to induce head pain, even in patients studied during an active cluster phase and its relevance to the pathogenesis of cluster headache remains doubtful.

A significantly greater proportion of patients giving a dietary history developed headache after oral tyramine, though this phenomenon was less evident after intravenous tyramine (table 2). It should be remembered, however, that these experiments were performed as open studies, without placebo, as their main purpose was the assessment of blood pressure rise, rather than development of headache. Headache onset after both oral and intravenous tyramine was substantially later than the pressor response and headache intensity was directly related to its speed of onset but not to the magnitude of pressor response. Thus it is unlikely that catecholamine release mechanisms by which the tyramine pressor effect is usually explained were responsible for the development of these headaches. The mechanism remains to be established.

JTL and RP were supported by the Migraine Trust. We are grateful to Miss S Tree (Pharmacist at St. Bartholomew's Hospital) for supplies of intravenous tyramine, and Mrs L Reveley (Pharmacist at Charing Cross Hospital) for supplies of oral tyramine. The automatic sphygmomanometer was loaned by Mr Jim Reck of Bard Medical Ltd.

\section{References}

${ }^{1}$ Blackwell B. Adverse effects of antidepressant drugs. Drugs 1981;21:201-19.

${ }^{2}$ Blackwell B, Marley E, Price J, Taylor D. Hypertensive interactions between monoamine oxidase inhibitors and foodstuffs. Br J Psychiat 1967;113:349-65.

${ }^{3}$ Hanington E. Preliminary report on tyramine headache. Br Med J 1967;2:550-1.

${ }^{4}$ Hanington E, Horn M, Wilkinson M. Further observations on the effects of tyramine. In: Cochrane AL, ed. Background to Migraine: 3rd Migraine Symp. London: Heinemann 1970:113-9. 
${ }^{5}$ Donnelly CH, Murphy DL. Substrate- and inhibitorrelated characteristics of human platelet monoamine oxidase. Biochem Pharmacol 1977;26:853-8.

- Sandler M, Youdim MBH, Southgate J, Hanington E. The role of tyramine in migraine: some possible biochemical mechanisms. In: Cochrane AL, ed. Background to Migraine: 3rd Migraine Symp. London, Heinemann 1970:103-12.

${ }^{7}$ Sicuteri F, Buffoni F, Anselmi B, del Bianco PL. An enzyme (MAO) defect on the platelets in migraine. Res Clin Stud Headache 1972;3:245-51.

${ }^{8}$ Glover V, Sandler M, Grant E, Rose FC, Orton D, Wilkinson M, Stevens D. Transitory decrease in platelet monoamine oxidase activity during migraine attacks. Lancet 1977;i:391-3.

${ }^{9}$ Bussone G, Giovannini P, Boiardi A, Boeri R. A study of the activity of platelet monoamine oxidase in patients with migraine headaches of with 'cluster headaches'. Eur Neurol 1977;15:157-62.

${ }^{10}$ Sandler M, Youdim MBH, Hanington E. A phenylethylamine oxidizing defect in migraine. Nature 1974;250:335-7.

" Glover V, Peatfield R, Zammit-Pace R, Littlewood J, Gawel M, Rose FC, Sandler M. Platelet monoamine oxidase activity and headache. J Neurol Neurosurg Psychiatry 1981;44:786-90.

${ }^{2}$ Burn JH, Rand MJ. The action of sympathomimetic amines in animals treated with reserpine. $J$ Physiol (Lond) 1958;144:314-36.

${ }^{13}$ Langer SZ, Draskoczy PR, Treudelenburg U. Time course of the development of supersensitivity to various amines in the nictitating membrane of the pithed cat after denervation or decentralization. J Pharmac Exp Ther 1967;157:255-73.

${ }^{14}$ Brandao F, Rodrigues-Pereira E, Monteiro JG, Osswald W. Characteristics of tyramine induced release of noradrenaline: mode of action of tyramine and metabolic fate of the transmitter. Arch Pharmac 1980;311:9-15.

${ }^{15}$ Ghose K, Coppen A, Carroll D. Studies of the interactions of tyramine in migraine patients. In: Greene R, ed. Current Concepts in Migraine Research. New York, Raven Press, 1978:89-95.

${ }^{16}$ Ghose K, Coppen A, Carroll D. Intravenous tyramine response in migraine before and during treatment with indoramin. Br Med J 1977;1:1191-3.

${ }^{17}$ Elsworth JD, Glover V, Reynolds GP, Sandler M, Lees AJ, Phuapradit P, Shaw KM, Stern GM, Kumar P. Deprenyl administration in man: a selective monoamine oxidase B inhibitor without the 'cheese effect'. Psychopharmacology 1978;57:33-8.

${ }^{18}$ Sandler M, Glover V, Ashford A, Esmail A. The inhibition of tyramine oxidation and the tyramine hypertensive response ("cheese effect") may be independent phenomena. J Neural Transmiss 1980;48:241-7. 